\title{
Glutathione conjugation in male reproductive system: Studies on glutathione-S-transferase of bull and boar epididymis ${ }^{\boldsymbol{*}}$
}

\author{
Agata Ciszewska-Piłczyńska and Anna Barańczyk-Kuźma ${ }^{凶}$ \\ Chair and Department of Biochemistry, The Medical University of Warsaw, S. Banacha 1, \\ 02-097 Warszawa, Poland
}

Received: 1 December, 1999; accepted: 24 February, 2000

Key words: glutathione-S-transferase, glutathione conjugation, epididymis, bull, boar

\begin{abstract}
Male reproductive organs are extremely sensitive to the negative influence of toxic environmental factors as well as drugs, and until now not many attempts have been made at studying the detoxication enzymes and the relationship between the activity of those enzymes and spermatozoa fertility. In the present work we studied cytosolic glutathione-S-transferases (GST, EC 2.5.1.18) from different parts (head, corpus and tail) of bull and boar epididymis. We isolated two molecular forms of GST from each part of epididymis, characterized their biochemical properties and examined the mechanism of the catalyzed reaction. On the basis of their substrate specificity and isoelectric point, the isoforms were found to belong to the near neutral GST class mi. All examined GST forms exhibited higher affinity towards GSH than towards 1-chloro-2,4-dinitrobenzene (CDNB) and bull epididymis GST forms showed biphasic Lineweaver-Burk double reciprocal curves in the presence of GSH as a variable substrate. Boar epididymis anionic GST had the -SH groups both in the GSH and the CDNB binding place, whereas the cationic GST form - arginine residues in the CDNB binding place. Bull epididymis GST forms contained neither thiol nor arginine residues essential for catalytic activity.
\end{abstract}

Male reproductive organs are particularly active, both physiologically and metabolically $[1,2]$. A great number of highly reactive and potentially toxic, electrophilic compounds occurring in the external environment such as products of the chemical industry or drugs, as well as endogenous biologically active compounds may disturb the process of spermatozoa production and maturation [1].

The metabolic pathway of chemical compounds is an enzymatic, two stage process, named phase I and phase II [3]. Glutathione

\footnotetext{
This work was supported by a Grant from the Medical University of Warsaw.

${ }^{\circledR}$ Correspondence should be addressed to: Prof. Anna Barańczyk-Kuźma, tel: (48 22) 822 7493; fax: (48

22) 658 0679; e-mail: akuzma@amwaw.edu.pl

Abbreviations: GST, glutathione-S-transferase; GSH, reduced glutathione; CDNB, 1-chloro-2,4-dinitrobenzene; EtA, ethacrinic acid; p-NBCl, p-nitrobenzyl chloride; BSP, bromosulphophthaleine; DCNB, 1,2-dichloro-4-nitrobenzene; NEM, $N$-ethylmaleimide; PG, phenylglyoxal.
} 
conjugation catalyzed by glutathione- $S$ transferase (GST, EC 2.5.1.18) is one of the most important phase II biotransformation reactions of reduced glutathione with a variety of reactive endo- and exogenous electrophiles. Glutathione- $S$-transferases represent a great family of ubiquitous cytosolic or membrane-bound enzymes which display distinct catalytic properties and play separate roles in the biotransformation and detoxication processes [4-7]. The cytosolic enzymes encoded by at least five related gene families are designated alfa, mi, pi, sigma and theta, whereas the membrane-bound GSTs are encoded by a single gene $[5,7,8]$. The existing evidence suggests that the specific tissue pattern of GSTs expression, as well as overlapping substrate specificities towards a number of highly reactive compounds, determines the sensitivity of cells to a broad spectrum of toxic chemicals [4, $5,7,8]$. The active center of mammalian glutathione- $S$-transferase contains separate places for binding: a hydrophobic, electrophilic acceptor substrate (place $\mathrm{H}$ ) and a nucleophilic site for reduced glutathione (place G) [6, 7, 9, 10]. The mechanism of the GST catalysed reaction consists in a nucleophilic attack of the sulfur atom of reduced glutathione on the electrophilic substrate, yielding the thioether bond [5, 11, 12]. This GSH conjugation reaction finally leads to the formation of mercapturic acids, usually less toxic and less reactive substances, which can be readily excreted from the organism with urine $[11,13,14]$. In addition to their catalytic activity, GSTs can also function as the intracellular binding and transport proteins of non-substrate, hydrophobic ligands [5, 15]. Since among the ligands there are also drugs, these enzymes are believed to be responsible for multidrug resistance [16, 17].

In our previous studies we demonstrated the presence of both, cytosolic and microsomal glutathione-S-transferases in boar testis, the organ where spermatozoa are produced [18]. In the present work, we have isolated cytosolic GSTs from different parts of bull and boar epididymides, the organs responsible for maturation and storage of spermatozoa.

\section{MATERIALS AND METHODS}

Chemicals. All chemicals and reagents were of the highest grade commercially available.

GST isolation procedure. The required tissues were obtained from the Animal Breeding Station, just after castration of the animals. Glutathione-S-transferase was extracted from different parts of epididymis (head, corpus, tail) in five volumes of $10 \mathrm{mM}$ sodium phosphate buffer, $\mathrm{pH}$ 7.4, containing $0.25 \mathrm{M}$ sucrose. The homogenate was centrifuged at $15000 \times \mathbf{g}$ for $15 \mathrm{~min}$. The cytosolic fraction was obtained by centrifugation of the extract at $100000 \times \boldsymbol{g}$ for $60 \mathrm{~min}$, and further purified by ion-exchange DEAE-cellulose chromatography, followed by CM-Sephadex and Sephadex G-100 column chromatography. DEAE-cellulose columns $(20 \mathrm{~cm} \times 1 \mathrm{~cm})$ were equilibrated with $10 \mathrm{mM}$ sodium phosphate buffer, pH 7.4, and CM-Sephadex as well as Sephadex G-100 columns $(20 \mathrm{~cm} \times 1 \mathrm{~cm})$ with $10 \mathrm{mM}$ sodium phosphate buffer, $\mathrm{pH}$ 6.5.

The profiles of separation of GST from the three parts of the epididymis were almost identical and represented each two forms of the enzyme in head, corpus and tail. Therefore in further experiments the GST forms isolated from the whole organ were used. All purification steps were carried out at $4^{\circ} \mathrm{C}$.

GST assay. The activity of glutathione-Stransferase was determined according to Habig et al. [14] in the modification of Fujita et al. [19] using: $1 \mathrm{mM}$ 1-chloro-2,4-dinitrobenzene (CDNB), $0.2 \mathrm{mM}$ ethacrinic acid (EtA), 1 $\mathrm{mM}$ p-nitrobenzyl chloride (p-NBCl), $0.03 \mathrm{mM}$ bromosulphophthaleine (BSP), $1 \mathrm{mM} \mathrm{1,2-di-}$ chloro-4-nitrobenzene (DCNB), and $1 \mathrm{mM}$ or $0.25 \mathrm{mM}$ reduced glutathione (GSH) as the nucleophilic substrate.

Protein determination. Protein was determined according to Lowry et al. [20], with 
crystalline bovine serum albumin as a standard.

Kinetic studies. For kinetic studies GSH or CDNB were used as the variable substrate. $K_{\mathrm{m}}$ values were calculated by the method of Eisenthal \& Cornish-Bowden [21].

Thermal stability. To study the thermal stability of GST enzyme samples were preincubated in a shaker bath at various temperatures for $15 \mathrm{~min}$, then the samples were cooled to $4^{\circ} \mathrm{C}$, and assayed for GST activity after adding buffer and substrates.

Molecular mass determination. The molecular mass of GST was determined on Sephadex G-100 chromatography columns according to Andrews [22], using as standards: horse myoglobin (17 kDa), egg albumin (45 $\mathrm{kDa})$, bovine serum albumin (67 $\mathrm{kDa})$ and aldolase (158 kDa).

Polyacrylamide gel electrophoresis and isoelectric focusing. Polyacrylamide gel electrophoresis was run at $\mathrm{pH} 5.5$ according to Sakai \& Gross [23], and at $\mathrm{pH} 8.9$ according to Davis [24]. Isoelectric points of GST forms were determined by agarose gel electrophoresis with ampholine at $\mathrm{pH}$ 3.5-10.0, according to LKB instructions.

Studies with N-ethylmaleimide (NEM) and phenylglyoxal (PG). The influence of NEM and PG on GST activity was investigated after $10 \mathrm{~min}$ preincubation of the enzyme at $37^{\circ} \mathrm{C}$ in the presence of $100 \mathrm{mM}$ sodium phosphate buffer, $\mathrm{pH}$ 6.5, and the compound studied. In the experiments on the effect of substrates on the enzyme treated by NEM or PG, $1 \mathrm{mM}$ CDNB or $1 \mathrm{mM} \mathrm{GSH}$ was included in the preincubation mixture.

\section{RESULTS AND DISCUSSION}

In the presence of 1-chloro-2,4-dinitrobenzene as a standard electrophilic substrate, glutathione-S-transferase activity in head, corpus and tail of epididymides was similar but it was slightly higher in bull than in boar tissue (Table 1). In comparison to the activity of bull testis GST, it was about 2-times lower (not shown) and with respect to that of boar it was about 20-times lower [18]. In bull and boar spermatozoa and in seminal fluid, GST activity was much lower than either in testis or in epididymis of the two species studied (not shown). In rat epididymis GST activity was 1.5- and 3-times as high as in bull and boar epididymis, respectively [25].

Mammalian GSTs exhibit broad and partially overlapping substrate specificities towards a large number of structurally unrelated substances of mutagenic or carcinogenic activity, as well as towards pharmacologically active substances [3, 5, 6, 8]. The specific activity of GST from the two species studied was the highest with CDNB, and it was about 1.5-times higher for bull than for boar epididymis (Table 2). The specific activity of GST with p-NBCl and EtA was similar in bull and boar epididymides, but with DCNB and BSP it was higher for bull enzyme (Table 2).

In our previous studies we demonstrated the presence of two different molecular GST forms in bull testis, which were isolated from the cytosolic and from the microsomal fractions respectively, by DEAE-cellulose and CM-Sephadex ion-exchange chromatography [18]. In the present studies, two molecular forms of GST were isolated from each of the three parts of bull and boar epididymis. The main form in bull epididymis was the cationic one (not adsorbed on DEAE-cellulose chromatography column) which contained about $80 \%$ of the total GST activity, whereas in boar epididymis the main enzymatic activity (about $60-70 \%$ of the total) was connected with the anionic form (adsorbed on DEAE-cellulose and eluted with a linear $\mathrm{KCl}$ gradient).

The two separated forms differed in the values of pI, which as estimated by agarose gel electrophoresis, were 5.5 and 5.2 for the anionic GSTs, and 6.6. and 6.9 for the cationic GST forms of bull and boar epididymis, respectively. On the basis of their isoelectric points, these forms may be classified as near-neutral (class mi), similarly as GSTs iso- 
lated from hamster (pI 5.9-6.8) and from human (pI 5.2) testes [26-28]. In human testis an acidic form of $\mathrm{pI} 4.4$ belonging to class $p i$, as well as basic alpha class forms (pI 8.36, 9.1 and 10.1) were also described [27, 28]. showed biphasic curves for both forms of bull epididymis glutathione-S-transferase (Fig. 1, Table 3). A marked substrate inhibition was observed at GSH concentration exceeding $2 \mathrm{mM}$. Similar double reciprocal biphasic

Table 1. Glutathione-S-transferase activity in different parts of bull and boar epididymis

\begin{tabular}{llc}
\hline Part of & Bull epididymis GST & Boar epididymis GST \\
\cline { 2 - 3 } epididymis & Activity $(\mu \mathrm{mol} / \mathrm{mg}$ protein $\times$ min $)$ \\
\hline head & $0.074 \pm 0.003$ & $0.051 \pm 0.006$ \\
corpus & $0.100 \pm 0.003$ & $0.069 \pm 0.003$ \\
tail & $0.095 \pm 0.002$ & $0.071 \pm 0.004$ \\
\hline
\end{tabular}

GST activity was assayed in cytosolic fraction using $1 \mathrm{mM}$ GSH and $1 \mathrm{mM}$ CDNB as described in Materials and Methods. Each value is the mean of five determinations \pm SEM.

The enzymes isolated from epididymides showed different mobility on polyacrylamide gel electrophoresis, and the $R_{\mathrm{f}}$ values were: 0.35 and 0.23 at $\mathrm{pH} 5.5$, and 0.75 and 0.42 at $\mathrm{pH} 8.9$ for bull and boar anionic glutathione-S-transferases, respectively. The $R_{\mathrm{f}}$ values estimated for the cationic bull and boar GSTs curves were also obtained for bull testis (not shown) and demonstrated for liver GSTs [10, 29]. Such kinetics suggests that at low (25-125 $\mu \mathrm{M}) \mathrm{GSH}$ concentration, CDNB is the first substrate bound at the enzyme active center (place H). On the contrary, at high (125-2000 $\mu \mathrm{M}) \mathrm{GSH}$ concentration, the asso-

Table 2. Substrate specificity of bull and boar epididymis glutathione-S-transferase

\begin{tabular}{lcc}
\hline Substrate & Bull epididymis GST & Boar epididymis GST \\
\cline { 2 - 3 } & \multicolumn{2}{c}{ Activity $(\mu \mathrm{mol} / \mathrm{mg}$ protein $\times$ min $)$} \\
\hline CDNB & $0.089 \pm 0.003$ & $0.064 \pm 0.004$ \\
DCNB & $0.007 \pm 0.001$ & $0.016 \pm 0.002$ \\
NBCl & $0.035 \pm 0.003$ & $0.038 \pm 0.003$ \\
BSP & $0.015 \pm 0.002$ & $0.022 \pm 0.001$ \\
EtA & $0.048 \pm 0.004$ & $0.041 \pm 0.002$ \\
\hline
\end{tabular}

Activity was assayed in cytosolic fraction as described in Materials and Methods. Each value is the mean of four determinations \pm SEM.

were: 0.49 and 0.60 at $\mathrm{pH} 5.5$, and 0.35 and 0.27 at $\mathrm{pH} 8.9$, respectively.

The affinity of all the examined GSTs forms for electrophilic CDNB was much lower than for GSH, and the affinity of the bull and boar anionic forms was higher than that of the cationic ones (Table 3). In the presence of reduced glutathione as a variable substrate, the Lineweaver-Burk double reciprocal plots ciation of reduced glutathione to the enzyme (place G) precedes CDNB joining. Such order of substrate- enzyme association might be necessary for optimal GST activity in the presence of various electrophilic substrates (e.g. drugs, xenobiotics).

The GST forms studied differed in their thermal stability. Bull anionic GST as well as boar cationic one were thermostable, whereas bull 
cationic and boar anionic GST forms were thermolabile: at $49^{\circ} \mathrm{C}$ they lost up to $60 \%$ and $80 \%$ of the initial activity, respectively (Fig. 2).

The molecular mass of both boar epididymis GSTs and the bull cationic form was $40-45 \mathrm{kDa}$, thus it was similar to that of the boar anionic GST being the only form protected against NEM inactivation by the presence of either substrate (Table 4). Neither GSH nor CDNB protected the activity of boar cationic GST (Table 4) and both bull GSTs (not shown).

Table 3. Substrate affinity of bull and boar epididymis glutathione-S-transferase

\begin{tabular}{lcccc}
\hline & \multicolumn{2}{c}{ Bull epididymis GST } & \multicolumn{2}{c}{ Boar epididymis GST } \\
\cline { 2 - 5 } Substrate & Anionic form & Cationic form & Anionic form & Cationic form \\
& $K_{\mathrm{m}}(\mu \mathrm{M})$ & $K_{\mathrm{m}}(\mu \mathrm{M})$ & $K_{\mathrm{m}}(\mu \mathrm{M})$ & $K_{\mathrm{m}}(\mu \mathrm{M})$ \\
\hline CDNB & $118 \pm 11$ & $400 \pm 18$ & $219 \pm 27$ & $800 \pm 12$ \\
GSH & $37 \pm 4$ & $216 \pm 10$ & $69 \pm 3$ & $100 \pm 4$ \\
\hline
\end{tabular}

GST activity was assayed with variable CDNB or GSH concentrations, as described in Materials and Methods. Each value is the mean of four determinations \pm SEM.

most known mammalian GSTs [5, 6, 8]. Only bull anionic GST, as well as equine liver GST had a higher molecular mass of about $60 \mathrm{kDa}$ [10].
Phenylglyoxal, a reagent specific for arginine residues, also inactivated all studied enzymes (Fig. 4). None of the substrates counteracted the decrease of activity of the bull

Table 4. The effect of substrate on the activity of boar epididymis glutathione-S-transferase inhibited by $N$-ethylmaleimide (NEM).

\begin{tabular}{lcccc}
\hline & \multicolumn{3}{c}{ Anionic GST } & Cationic GST \\
\cline { 2 - 5 } \multicolumn{1}{c}{ Substrate } & \multicolumn{5}{c}{ NEM (mM) } \\
\cline { 2 - 5 } & \multicolumn{5}{c}{1.0} & 0.5 & 1.0 \\
\cline { 2 - 5 } & $48 \pm 1$ & Activity (\%) & $32 \pm 1$ \\
None & $33 \pm 1$ & $48 \pm 2$ & $37 \pm 1$ \\
GSH & $61 \pm 4$ & $49 \pm 2$ & $48 \pm 2$ & $38 \pm 1$ \\
CDNB & $66 \pm 3$ & $45 \pm 2$ & $54 \pm 1$ & $38 \pm 1$ \\
\hline
\end{tabular}

GST activity was assayed after preincubation with NEM, using $1 \mathrm{mM}$ substrates, as described in Materials and Methods. The activity measured after preincubation without NEM was taken as $100 \%$. Each value is the mean of four determinations \pm SEM.

$N$-Ethylmaleimide, a sulfhydryl reagent, inactivated all the enzymes studied (Fig. 3). The most resistant to that compound was the anionic GST from bull epididymis, which was the only form that retained about $40 \%$ of the initial activity after preincubation with $5 \mathrm{mM}$ NEM (Fig. 3A). To define the location of -SH groups on GST, substrate protection experiments were carried out. They pointed to the epididymis GSTs or of the boar anionic form, whereas the activity of the boar cationic form was protected by CDNB but not by GSH (Tables 5, 6).

These data suggest that the bull epididymis glutathione-S-transferases contain neither thiol groups nor arginine residues which could be essential for their catalytic activity. These groups/residues are believed to take 


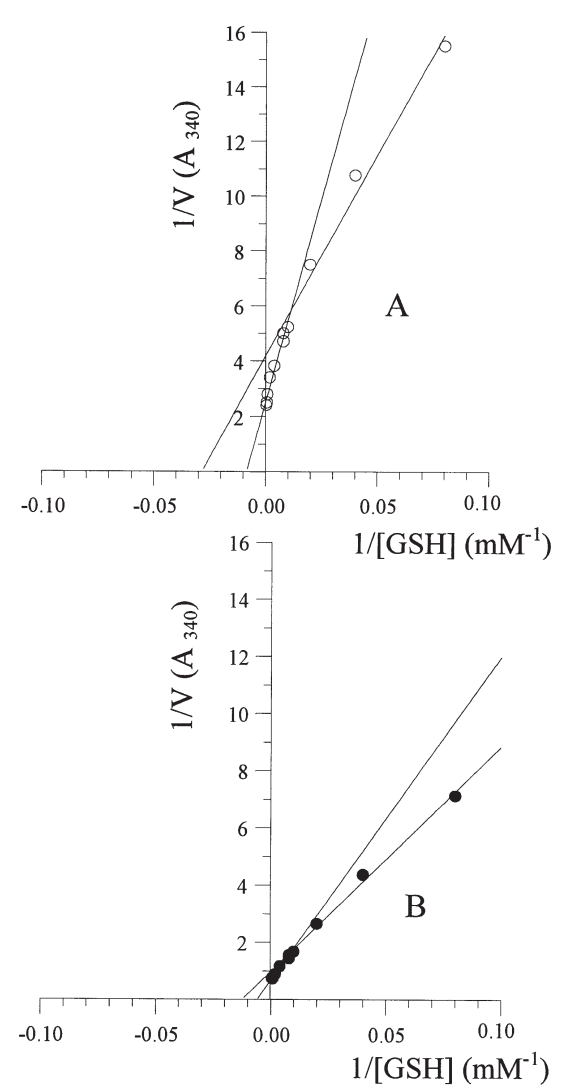

Figure 1. Lineweaver-Burk plots of bull epididymis anionic (A) and cationic (B) glutathione-Stransferases to GSH as the variable substrate.

The activity was assayed as described in Materials and Methods.

part in stabilizing a proper, active conformation of these enzymes. On the other hand, the boar epididymis anionic GST has thiol groups but not the arginine residues in both, $\mathrm{G}$ and $\mathrm{H}$ places, whereas the cationic form has arginine residues in the CDNB binding place $(\mathrm{H})$.

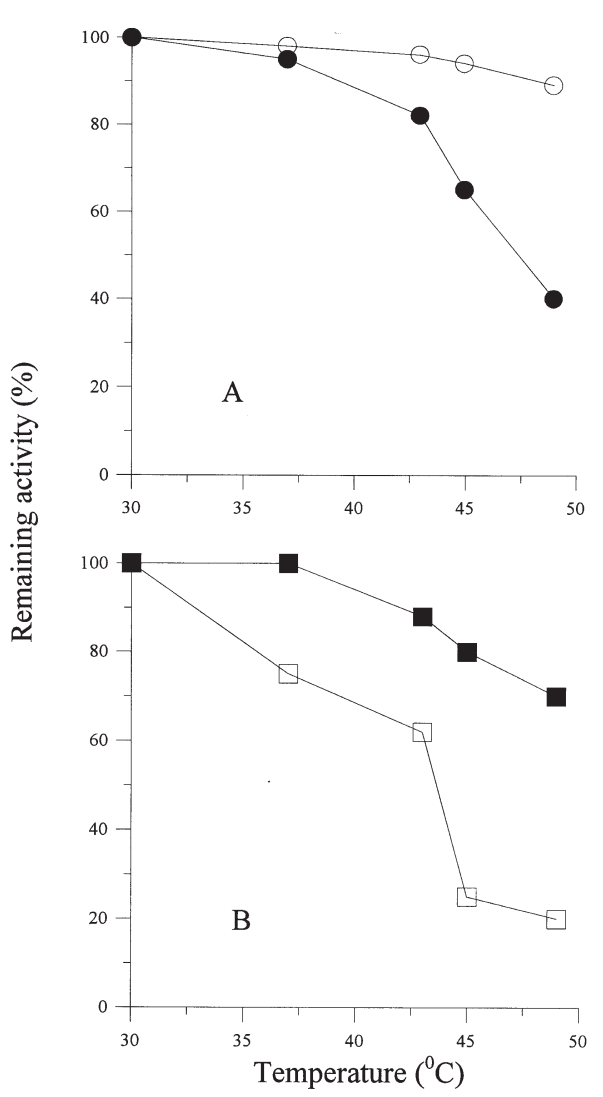

Figure 2. Thermostability of bull (A) and boar (B) epididymis glutathione-S-transferases.

GST activity was assayed as described in Materials and Methods. The activity without preincubation of the enzyme was taken as $100 \%$. Each value is the mean of three determinations. Bull anionic (•) and cationic

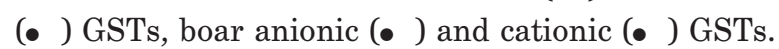

Arginine residues and thiol groups seem to be necessary for the proper conformation of the boar anionic and the cationic GST form, respectively.

Table 5. The effect of substrate on the activity of bull epididymis glutathione-S-transferase inhibited by phenylglyoxal (PG)

\begin{tabular}{lcccc}
\hline & \multicolumn{2}{c}{ Anionic GST } & \multicolumn{2}{c}{ Cationic GST } \\
\cline { 2 - 5 } Substrate & \multicolumn{5}{c}{ PG (mM) } \\
\cline { 2 - 5 } & 0.5 & 1.0 & 0.5 & 1.0 \\
\cline { 2 - 5 } & $56 \pm 1$ & Activity (\%) & $30 \pm 3$ \\
None & $27 \pm 3$ & $57 \pm 1$ & $33 \pm 1$ \\
GSH & $42 \pm 3$ & $18 \pm 3$ & $58 \pm 3$ & $36 \pm 1$ \\
\hline
\end{tabular}

GST activity was determined as described in Table 4 . Each value is the mean of four determinations \pm SEM. 


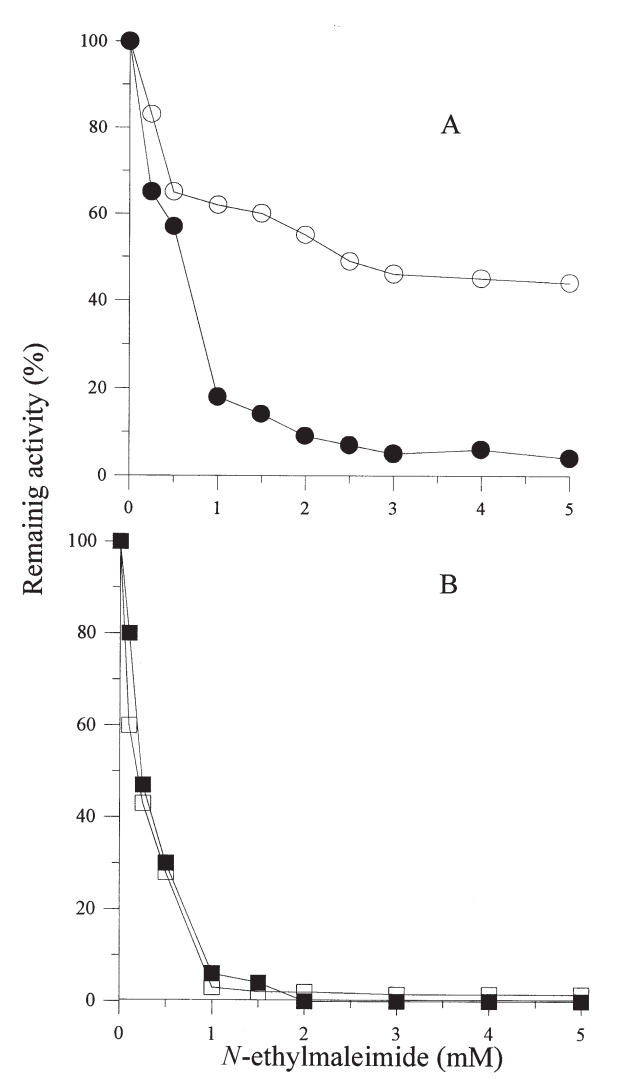

Figure 3. The effect of $N$-ethylmaleimide (NEM) on the activity of bull (A) and boar (B) epididymis glutathione-S-transferases.

GST activity was assayed as described in Materials and Methods. The activity after preincubation of the enzyme with the buffer was taken as $100 \%$. Each value is the mean of three determinations. The symbols used are as described for Fig. 2.

On the basis of the results presented, it can be concluded that glutathione-S-transferase present in all parts of the bull and boar

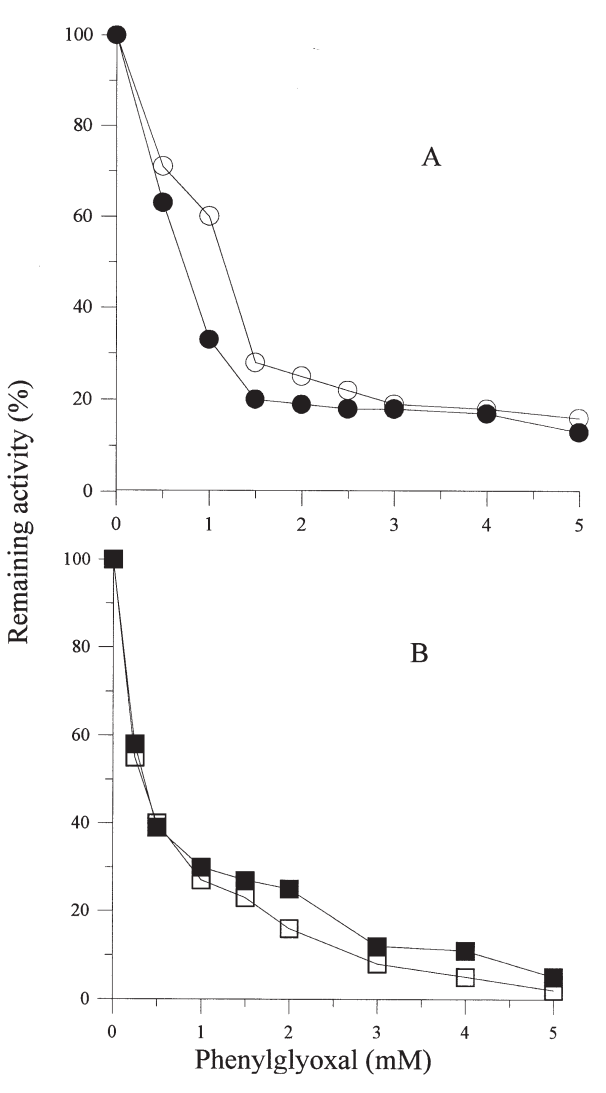

Figure 4. The effect of phenylglyoxal (PG) on the activity of bull (A) and boar (B) epididymis glutathione-S-transferases.

GST activity was assayed as described for Fig. 2. Each value is the mean of three determinations. The symbols used are as described for Fig. 2.

epididymides may be a part of the naturally occurring enzymatic barrier protecting the spermatozoa against the toxic effects of various electrophilic compounds. Further studies

Table 6. The effect of substrate on the activity of boar epididymis glutathione-S-transferase inhibited by phenylglyoxal (PG)

\begin{tabular}{|c|c|c|c|c|}
\hline \multirow{4}{*}{ Substrate } & \multicolumn{2}{|c|}{ Anionic GST } & \multicolumn{2}{|c|}{ Cationic GST } \\
\hline & \multicolumn{4}{|c|}{$\mathrm{PG}(\mathrm{mM})$} \\
\hline & 0.5 & 1.0 & 0.5 & 1.0 \\
\hline & \multicolumn{4}{|c|}{ Activity (\%) } \\
\hline None & $55 \pm 1$ & $39 \pm 6$ & $55 \pm 3$ & $35 \pm 1$ \\
\hline GSH & $46 \pm 5$ & $30 \pm 1$ & $58 \pm 1$ & $40 \pm 2$ \\
\hline CDNB & $58 \pm 1$ & $45 \pm 4$ & $78 \pm 3$ & $51 \pm 1$ \\
\hline
\end{tabular}

GST activity was determined as described in Table 4 . Each value is the mean of four determinations \pm SEM. 
are required to confirm the role of GST in spermatozoa fertility.

\section{R E F E R E N C E S}

1. Mann, T. (1964) Male accessory organs of reproduction, and their secretory product: the seminal plasma; in The Biochemistry of Semen and of the Male Reproductive Tract (Mann, T., ed.) pp. 37-78, Methuen \& CO LTD, London, Wiley, J. \& Sons Inc., New York.

2. Glover, T.D. \& Nicander, L. (1971) Some aspects of structure and function in mammalian epididymis. J. Reprod. Fert. (Suppl.) 13, 3950 .

3. Gorrod, G. \& Gibson, P.S. (1986) Pathways of drug metabolism; in Introduction to Drug $\mathrm{Me}$ tabolism (Gorrod, G. \& Gibson, P.S., eds.) pp. 1-35, Chapman \& Hall, London.

4. Jakoby, W.B. (1978) The glutathione-S-transferases: A group of multifunctional detoxication proteins. Adv. Enzymol. 46, 383-414.

5. Mannervik, B. (1985) The isoenzymes of glutathione transferase. Adv. Enzymol. 57, 357-417.

6. Mannervik, B. \& Danielson, U.H. (1988) Glutathione transferases: Structure and catalytic activity. CRC Crit. Rev. Biochem. 23, 283-337.

7. Armstrong, R. (1994) Glutathione-S-transferase: Structure and mechanism of an archetypical detoxication enzyme. Adv. Enzymol. 69, 1-44.

8. Pickett, C.B. \& Lu, A.Y.H. (1989) Glutathione$S$-transferases: Gene structure, regulation and biological function. Annu. Rev. Biochem. 58, 743-764.

9. Adang, A.E.P., Brussee, J., van der Gen, A. \& Mulder, G.J. (1990) The glutathione-binding site in glutathione-S-transferases. Biochem. J. 269, 47-54.
10. D'Silva, C. (1990) Inhibition and recognition studies on the glutathione-binding site of equine liver glutathione-S-transferase. Biochem. J. 271, 161-165.

11. Ketterer, B. \& Mulder, G.J. (1990) Glutathione conjugation; in Conjugation Reactions in Drug Metabolism (Mulder, G.J., ed.) pp. $307-364$.

12. Orrenius, S. \& Moldeus, P. (1984) The multiple roles of glutathione in drug metabolism. Trends Pharmacol. Sci. 5, 432-435.

13. Boyland, E. \& Chasseaud, L.F. (1967) Enzyme-catalysed conjugation of glutathione with unsaturated compounds. Biochem. J. 104, 95-102.

14. Habig, W.B., Pabst, M.J. \& Jakoby, W.B. (1974) Glutathione-S-transferases: The first enzymatic step in mercapturic acid formation. J. Biol. Chem. 249, 7130-7139.

15. Listowsky, I., Abramowitz, M., Homma, H. \& Niitsu, Y. (1988) Intracellular binding of hormones and xenobiotics by glutathione- $S$-transferases. Drug Metab. Rev. 19, 305-318.

16. Morrow, S. \& Cowan, K.H. (1990) Glutathione-S-transferase and drug resistance. Cancer Cells. 2, 15-22.

17. Hayes, J.D. \& Pulford, D.J. (1995) The glutathione- $S$-transferase supergene family: Regulation of GST and the contribution of the isoenzymes to cancer chemoprotection and drug resistance (Review). Crit. Rev. Biochem. Mol. Biol. 30, 445-600.

18. Ciszewska-Piłczyńska, A. \& BarańczykKuźma, A. (1992) Glutathione-S-transferase from boar testis: Properties of the cytosolic and microsomal forms. Acta Biochim. Polon. 39, 139-145.

19. Fujita, E., Kitagawa, H., Ishizawa, H., Suzuki, T. \& Kitani, K. (1985) Age associated alterations in hepatic glutathione-S-transferase activity. Biochem. Pharmacol. 34, 3891-3894. 
20.Lowry, O.H., Rosebrough, N.J., Farr, A.L. \& Randall, R.J. (1951) Protein measurement with the Folin phenol reagent. J. Biol. Chem. 193, 265-275.

21. Eisenthal, R. \& Cornish-Bowden, A. (1974) The direct linear plot. A new graphical procedure for estimating enzyme kinetic parameters. Biochem. J. 139, 715-720.

22. Andrews, G. (1964) Estimation of the molecular weights of proteins by Sephadex gel-filtration. Biochem. J. 91, 222-233.

23. Sakai, T. \& Gross, J. (1967) Some properties of the products of reaction of tadpole collagenase with collagen. Biochemistry 6, 518-521.

24. Davis, B.J. (1964) Disc-electrophoresis II. Method and application to human serum proteins. Ann. N.Y. Acad. Sci. U.S.A. 121, 404427.

25. Meyer, L.G., Christodoulides, O., Nyan, R., Schuster, B. \& Ketterer, B. (1983) A comparison of the glutathione transferases (GST) of three extrahepatic organs with different functions - the adrenal, the lactating mammary gland and the male reproductive system; in Extrahepatic Drug Metabolism and Chemical Carcinogenesis (Rydstrom, I., Montelius, J. \& Bengtsson, M., eds.) pp. 198-200, Elsevier, Amsterdam.

26. Boggards, J.J.P., van Ommen, B. \& van Bladderen, P.J. (1992) Purification and characterization of eight glutathione-S-transferase isoenzymes of hamster. Biochem. J. 286, 383-388.

27. Aceto, A., Ilio di, C., Angelucci, S., Felaco, M. \& Federici, G. (1989) Glutathione transferase isoenzymes from human testis. Biochem. Pharmacol. 38, 3653-3660.

28. Campbell, E., Takahashi, Y., Abramovitz, M., Peretz, M. \& Listowsky, I. (1990) Distinct human testis and brain $\mu$-class glutathione- $S$ transferase. J. Biol. Chem. 265, 9188-9193.

29.Pabst, M.J., Habig, W.H. \& Jakoby, W.B. (1974) Glutathione-S-transferase A. A novel kinetic mechanism in which the major reaction pathway depends on substrate concentration. J. Biol. Chem. 249, 7140-7150. 